\title{
A Generalizable Framework for Multi-Scale Auditing of Digital Learning Provision in Higher Education
}

\author{
Samuel R. P-J. Ross \\ University of Leeds, Okinawa Institute of Science and Technology, and Trinity College Dublin \\ Veronica Volz, Matthew K. Lancaster, and Aysha Divan \\ University of Leeds
}

\begin{abstract}
It is increasingly important that higher education institutions be able to audit and evaluate the scope and efficacy of their digital learning resources across various scales. To date there has been little effort to address this need for a validated, appropriate, and simple-to-execute method that will facilitate such an audit, whether it be at the scale of an individual program, department, faculty, or institution. The data are of increasing value to ensure institutions maintain progress and equity in the student experience as well as for deployment and interpretation of learning analytics. This study presents a generalizable framework for auditing digital learning provision in higher education curricula. The framework is contextualized using a case study in which the audit is conducted across a single faculty in a research-intensive UK university. This work provides academics and higher education administrators with key principles and considerations as well as example aims and outcomes.
\end{abstract}

Keywords: digital learning, audit, evaluation, learning resources, analytics, blended learning

Ross, S.R.P-J., Volz, V., Lancaster, M.K., \& Divan, A. (2018). A generalizable framework for multi-scale auditing of digital learning provision in higher education. Online Learning, 22(2), 249-270. doi:10.24059/olj.v22i2.1229

\section{A Generalizable Framework for Multi-Scale Auditing of Digital Learning Provision in Higher Education}

Digital learning resources, defined here as "learning content facilitated by technology with some element of student control over time, place, path or pace" (Horn, Staker, \& Christensen, 2015), are increasingly being recognized to play a valuable role in the student learning experience (Fink, 2003; Gilbert, Morton, \& Rowley, 2007; Weigel, 2002; Wong, 2013). Digital supplementation and enhancement of learning has frequently been shown to have positive effects on the student experience, both in terms of student grades (e.g., Papastergiou, 2009) and student satisfaction (Golden, McCrone, Walker, \& Rudd, 2006; Davies, Mullan, \& Feldman, 2017); 
indeed, recent surveys of students indicate the importance of having digitally skilled staff providing appropriate experiences to support learning as well as the students' perception of the value of having technology deployed to support their education (Sclater \& Mullan, 2017).

With the continued design and implementation of more interactive, engaging, and even personalized experiences, integration of digital learning in teaching settings continues to show promise (Wagner, 2006). Accordingly, the majority of higher education institutions are rapidly integrating digital resources into their programs of study (Garrison \& Kanuka, 2004; Hiltz \& Turoff, 2005; Brown et al., 2014), driven by considerable recent advances in the availability and range of such resources along with advances in the technology and theory behind their use (Alpert \& Blitzer, 1970; Hiltz \& Turoff, 2005; Littlejohn \& Pegler, 2007; Brown, Jacobsen, \& Lambert, 2014; Reiser, 2017). Indeed, it has become the expected norm that programs will offer digital resources to support teaching, with students seeking out digital resources to support their learning if they are not specifically offered by the institution. With this increasing adoption of digital learning resources, the onus is now on the institution to offer a curated, tailored experience to optimally support learning and ensure the accessibility and appropriateness of such support. Naturally, some areas - be they institutions, faculties (i.e., a division within a higher education institution comprising one or more related subject areas), or subdisciplines-begin to fall behind in this "digital revolution," and institutions that fail to meet these expectations are increasingly viewed as giving substandard provision and support (Sheehan \& Mihailidis, 2007; Bigum \& Rowan, 2008; Davies et al., 2017).

Digital learning resources may be adopted in higher education in a variety of contexts and to varying degrees. At one end of the spectrum are completely digital online courses, such as Massive Open Online Courses (MOOCs; Christensen et al., 2013; Kop, 2011). Conversely, there are currently numerous smaller ways that digital technology or resources can be integrated into traditionally nondigital teaching and learning practices, such as for species identification in biology field courses (Jeno, Grytnes, \& Vandvik, 2017); professional development and peer review (Collins, Cook-Cottone, Robinson, \& Sullivan, 2004; Laru, Järvelä, \& Clariana, 2012); music creation and evaluation using individual mobile applications (Birch, 2017); and for enhancing learning through the use of interactive, responsive games (Kiili, 2005). The use of such tools and resources needs to be optimized for and appropriate to the learning context, but deployment is frequently spearheaded by enthusiasts or by localized initiatives in selected areas of a curriculum or overall learning experience. This organic and relatively unmoderated spread of digital tools and resources within the curriculum can lead to large variation within the student experience (Gilbert et al., 2007), which is important to understand and visualize if student feedback and the overall student experience are to be analyzed appropriately and developed in a constructive, strategic, and progressive manner.

As such, the importance of measuring and monitoring the implementation of different forms of digital learning and associated resources within higher education institutions is continually growing. Although Leacock and Nesbit (2007) present a framework for evaluation of individual learning resource objects in terms of their quality, there is currently no published method of measuring the deployment of digital learning in higher education institutions. Such a methodology is increasingly required to allow monitoring of trends as well as progression, variability, and development of the efficacy of digital learning alongside the uptake and deployment of blended learning (Adams Becker et al., 2017). This has become particularly relevant in the UK with the introduction of the Teaching Excellence Framework (TEF; Business, 
Innovation and Skills Committee, 2016), putting the onus on institutions to demonstrate progression in the development of teaching excellence and resources to support students. Another key driver to implement such an audit is the increasing use of learning analytics to assess key indices of student progression and attainment, potentially permitting early intervention and individual tailoring of the learning experience to optimize progression (Sclater \& Mullan, 2017). Such information is potentially uninformative if not supplemented with key data on the elements of the learning experience the student encounters.

This study presents a generalizable framework for auditing digital learning in higher education institutions, with the aim of providing a method that allows higher education administrators and academics to monitor and evaluate the deployment of digital learning resources and techniques. A case study audit of digital learning conducted across a biological sciences department in a research-intensive UK university is presented as an illustrative example of how the framework can be implemented to address specific key aims and objectives. It also illustrates how such an audit can be used as a developmental tool in the longer term by setting baseline values of digital learning provision. This framework aims at generalizability and thus presents ideas for extensions beyond the scope of the present study. This study fills a critical gap in how audits of digital learning resources could be conducted in a higher education context.

\section{Methods}

\section{Study Design}

This study aimed to establish a robust means to audit digital learning, allowing comparison of resource use and types of resource deployed and, consequently, help address issues regarding equity and development of the learning experience. The resultant tool and approach are also intended to permit monitoring of progress, feed into future work considering the efficacy of resource use, and intrinsically encourage development. The approach taken is an evaluative case study using an embedded single-case design permitting a holistic overview but also analysis and cross-comparison of subunits (see Yin, 2014). The audit tool was initially conceptualized, developed, and then trialled using the data available locally, forming the case study presented here.

\section{Audit Method}

A flagship audit of digital learning resources was conducted in a large faculty within a research-intensive UK university. This audit had the key aim of being able to measure the deployment of digital learning resources, and support of teaching through such resources, at multiple levels within an educational institution. The basic unit used for assessment was a module. A module represents a largely self-contained unit of teaching on perhaps a single topic or group of related topics or concepts. Such modules could consist of material developed over several weeks or over shorter periods, but for the purposes of this schema they represent a unit that can be clearly delineated and defined as a distinct element of taught content contributing to the overall student learning experience. Modules may vary in their format and assessment style. Some modules may be entirely lecture based and assessed solely by written exam in a manner very traditional in higher education, while others may be entirely coursework based, research focused, and operated with or without lectures, exams, or practical classes. A module is a convenient unit of assessment for many institutions since such units of classes are usually readily identified as such by students and staff alike and typically have their own space for resources on learning management systems (LMS). 
Each module was audited individually as part of the protocol for evidence of digital teaching and learning resources. This involved reviewing the LMS space and associated materials for any digital resources and recording their quantity and nature (see Table 1). Module staff were consulted via e-mail to confirm the findings and ensure the identification of resources that might not be linked to the LMS space for the module. This resulted in a module-by-module breakdown of the volume of digital assets deployed for use in learning and teaching. The full audit process is outlined in Table 1.

Table 1.

The Audit Framework

\begin{tabular}{|c|c|c|}
\hline Audit Stage & Purpose & Details of process \\
\hline$i$ & Decide what to audit & $\begin{array}{l}\text { Digital learning resources, other learning resources, examinations, teaching } \\
\text { audits, and blended learning resources are all options. }\end{array}$ \\
\hline$i i$ & Decide where to audit & $\begin{array}{l}\text { The scale at which the audit is being conducted (e.g., university level, faculty } \\
\text { level, school level, or specific degree program). }\end{array}$ \\
\hline$i i i$ & $\begin{array}{c}\text { Decide the aims/goals of the } \\
\text { project }\end{array}$ & $\begin{array}{l}\text { Is this an exploratory audit aimed at getting baseline values, one with specific } \\
\text { comparisons that need to be made (e.g., does A have more digital learning } \\
\text { resources than B?), or one with aims/goals set externally or at a higher level? }\end{array}$ \\
\hline$i v$ & Decide what to measure & $\begin{array}{l}\text { If measuring digital learning resources, then should they be partitioned } \\
\text { according to student value or some other measure? The example case study } \\
\text { presents a categorization of digital learning resources based on volume of } \\
\text { resource provision balanced with their anticipated interactivity value and role } \\
\text { in promoting digitally supported self-directed learning. }\end{array}$ \\
\hline$v$ & Conduct the audit & $\begin{array}{l}\text { This is generally a simple count, but it may require several hundred person } \\
\text { hours for large-scale audits. For reference, the faculty-level audit described in } \\
\text { this study took approximately } 400 \text { person hours. }\end{array}$ \\
\hline$v i$ & Confirm findings & $\begin{array}{l}\text { Check the accuracy of the audit by verifying with those who own or } \\
\text { contributed to the resources. }\end{array}$ \\
\hline vii & Visualize and interpret results & $\begin{array}{l}\text { Has the audit resulted in enough data to sufficiently address the aims/goals set } \\
\text { out in Stage iii? If not, continue auditing (Stage v). }\end{array}$ \\
\hline viii & Answer questions & $\begin{array}{l}\text { Report findings and answer questions or address aims/goals set out in audit } \\
\text { Stage iii. }\end{array}$ \\
\hline$i x$ & Revisit and monitor trends & $\begin{array}{l}\text { Most audits are not likely to be used as a single instance answering one } \\
\text { question, but rather as a tool for monitoring/evaluating long-term changes in } \\
\text { the audited unit. As such, an initial audit is necessary to establish baseline } \\
\text { values, but then planned follow ups at regular intervals should be considered } \\
\text { to monitor trends. }\end{array}$ \\
\hline$x$ & Respond to results & $\begin{array}{l}\text { After monitoring trends, audits should be followed by actions to allow for } \\
\text { improvement in areas that appear to be consistently underperforming or those } \\
\text { which could be used as beacons of good practice. }\end{array}$ \\
\hline
\end{tabular}

Note: Table presenting the recommended framework for conducting audits of digital learning, broken into Steps $i-x$. It is recommended that these steps be followed to ensure the success of such an audit.

Digital resource formats. To identify the type of digital resource being deployed, resources were each associated with discrete categories depending on their nature. Some resources are inherently more difficult to categorize than others, but broadly speaking, all resources could be matched to the categories presented in Table 2.

The resource format categories were ranked on a scale of 1 to 5 (lowest to highest, respectively) in terms of their considered interactivity value and contribution to enhancing the student learning experience (see Hill \& Hannafin, 2001; Song \& Hill, 2007; Traxler \& Kukulska-Hulme, 2005). At their most basic, resources are passive and, although useful, lack the interaction and feedback elements 
which encourage further exploration and interaction with the subject matter. Learning is generally considered to be enhanced if the number of interactions with the material via several differing viewpoints can be increased along with useful feedback to permit correction and reinforcement (Laurillard, 2002). This, of course, is situation and subject dependent and so must be tailored as appropriate. For this study, a team of experts utilizing blended learning locally discussed and trialled values as deemed appropriate to score the anticipated impact on student learning of the resources for this context. While such scoring has a high level of subjectivity and should be adapted based on further evidence as it becomes available and as an audit operates, the current values presented in this study aim at generalizability, with the interactivity of digital learning resources representing general patterns which should hold true across most contexts.

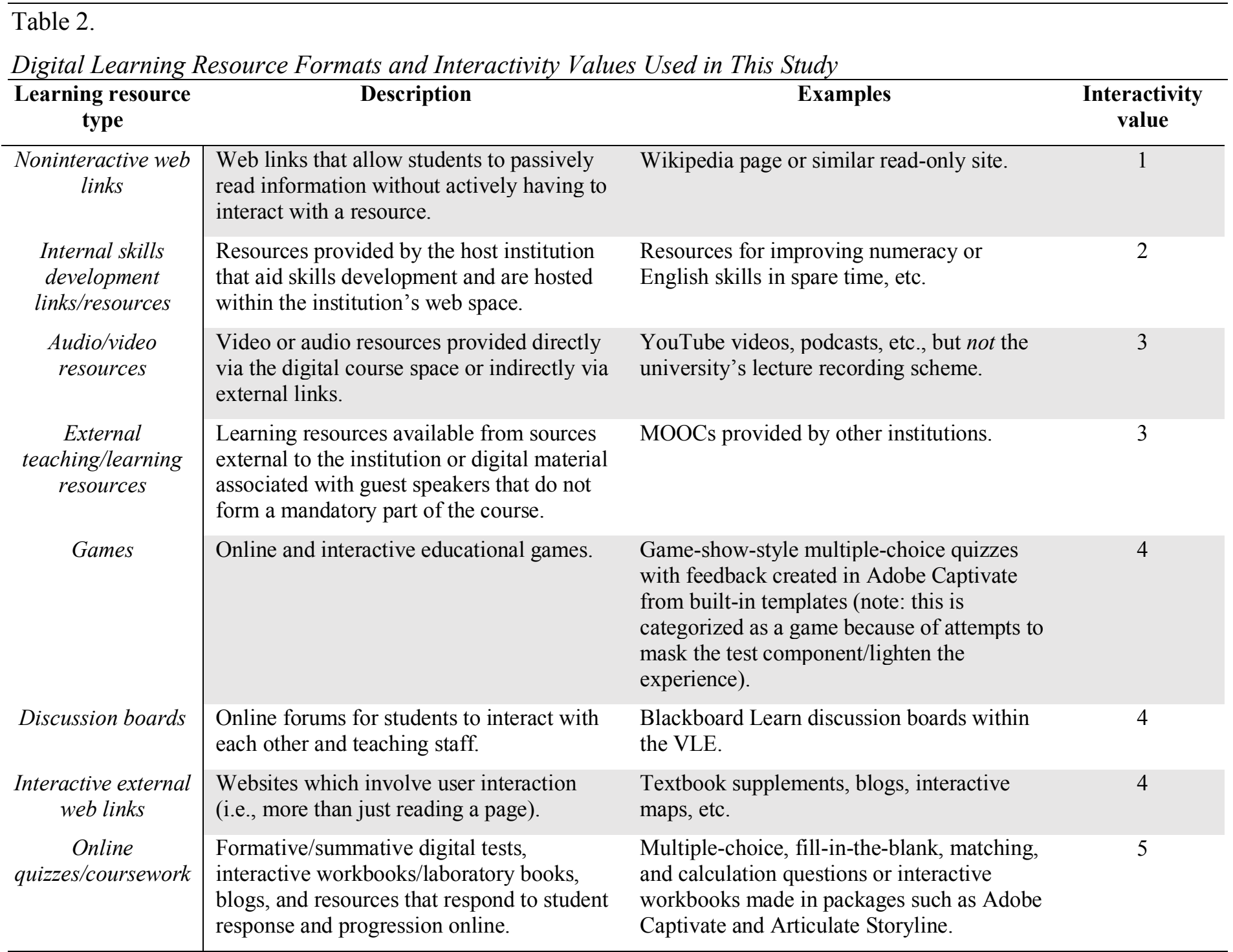

Note: Digital learning resources audited in the case study all fall into one of the categories presented here. Each category is accompanied by a description and example resource that would fall within that category. Additionally, this table provides interactivity values which can be used to weight digital learning resources by their a priori potential for self-directed student learning (see Equation 1), with higher values representing more interactive and engaging resource categories. 


\section{Digital Learning Score Formula}

Equation 1 shows the calculation for the digital learning score, which accounts for both quantity of resources and a weighting to account for the interactivity value of the resource. These scores are valuable ensuing data analysis and comparison.

$$
\mathrm{DL}_{\mathrm{S}}=1+\sum_{\text {Equation } 1}\left|\mathrm{DL}_{\mathrm{N}} \times \mathrm{DL}_{\mathrm{I}}\right| / \mathrm{C}
$$

Where DLs is the digital learning score, $\mathrm{DL}_{\mathrm{N}}$ is the total quantity of digital learning resources in a given category (see Table 1), $\mathrm{DL}_{\mathrm{I}}$ is the interactivity value assigned to each digital learning resource category (Table 1), and $\mathrm{C}$ is an absolute measure of course size. As such $\sum\left|\mathrm{DL}_{\mathrm{N}} \mathrm{X} \mathrm{DL}_{\mathrm{I}}\right|$ represents the sum of the absolute value of the quantity of each digital learning resource category when accounting for their interactivity. This is then standardized as a relative unit size for each course being audited (C). The basic unit here was a module, as defined above, but due to variation in the weighting or size of each module within a program of study undertaken by any student, it is necessary to account for potential bias. At many UK institutions, the weighting of teaching is defined by credits, where each module can be given a credit value representative of its taught content volume. As such, this was the most appropriate factor to use for weighting this audit. Normalization to credit value is therefore simply accomplished by dividing the summed product of $\mathrm{DL}_{\mathrm{N}}$ and $\mathrm{DL}_{\mathrm{I}}$ across all digital resource categories by the credit value of each module (C) (e.g., a 20 -credit module was divided by 20 , while a 40 -credit module was divided by 40 ).

By taking account of both the quantity $\left(\mathrm{DL}_{\mathrm{N}}\right)$ and interactivity $\left(\mathrm{DL}_{\mathrm{I}}\right)$ of digital resources, the digital learning score $\left(\mathrm{DL}_{\mathrm{S}}\right)$ can be assessed to check that it does not systematically bias the results of the audit toward courses of large size (and hence those that are naturally expected to have a greater quantity of resources) or those with few but highly interactive resources. This was the intended aim of this study: to approximately equate quantity with interactivity such that an increase in digital learning score across modules represents roughly even increases in both these components of a module's digital learning score, balancing the consideration of volume and estimated teaching value of resources (as verified in the illustrative case study that follows). This, of course, could be deliberately weighted to prioritize one or the other element.

\section{Case Study}

The core aim of this study is to outline how an audit of digital learning resources can be conducted at a large scale in a higher education setting. The concepts and practical application of this are explored through a case study of a digital learning audit in a biological sciences faculty in a research-intensive UK university. This is a large faculty with approximately 2,275 undergraduate students enrolled in taught programs at any one time and 160 teaching staff. This audit focused on modules that formed a compulsory or optional component of any single-honors undergraduate degree within the faculty for the 2015-16 academic year. The faculty operates taught programs within subject-orientated schools, designated here as School A, School B, School C, and School D. A total of 183 individual undergraduate taught modules are run within the faculty each academic year, ranging in content value from 10-60 credits, of which students must take 120 credits per academic year. The modules are units of teaching taken from a range of disciplines at the undergraduate degree level and, as such, represent the typical challenge of auditing a very diverse set of activities. Each module has its own digital space on Blackboard's Virtual Learning 
Environment (VLE; Blackboard, 2017) where students can find resources and support for each module.

The case study was undertaken to address the following key questions:

1. To what extent has digital learning been implemented across modules, degree programs, program levels, and schools within the faculty?

2. Where are the current gaps in provision and how might these gaps be reduced?

3. How can the results of this audit be used to inform a digital or blended learning strategy for the faculty?

\section{Results}

\section{Analysis of Digital Learning Score (DLs)}

All analyses were performed in R version 3.2.2 (R Core Team, 2016). To assess the scoring methodology, a Spearman's rank correlation between digital learning score (DLs) and raw volume of resources $\left(\mathrm{DL}_{\mathrm{N}}\right)$ for the case study example was produced. The results, as shown in Figure 1, reveal a significant positive relationship between volume of resource provision and anticipated interactivity and engagement (Spearman correlation $r=0.77, p<0.0001$ ). For the purposes of this audit's aims, this indicates that the weighting had appropriately balanced the scoring between the type of resource and the volume of provision, as desired. The presence of either a lower volume of highly interactive resources or many less interactive resources did not more heavily influence overall digital learning scores here. This suggests that despite less interactive resources being easier to develop and deploy, digital learning scores were not effectively penalized by investing more in one resource type than another, so DLs approximately equates the contribution of volume $\left(\mathrm{DL}_{\mathrm{N}}\right)$ with resource interactivity $\left(\mathrm{DL}_{\mathrm{I}}\right)$. 


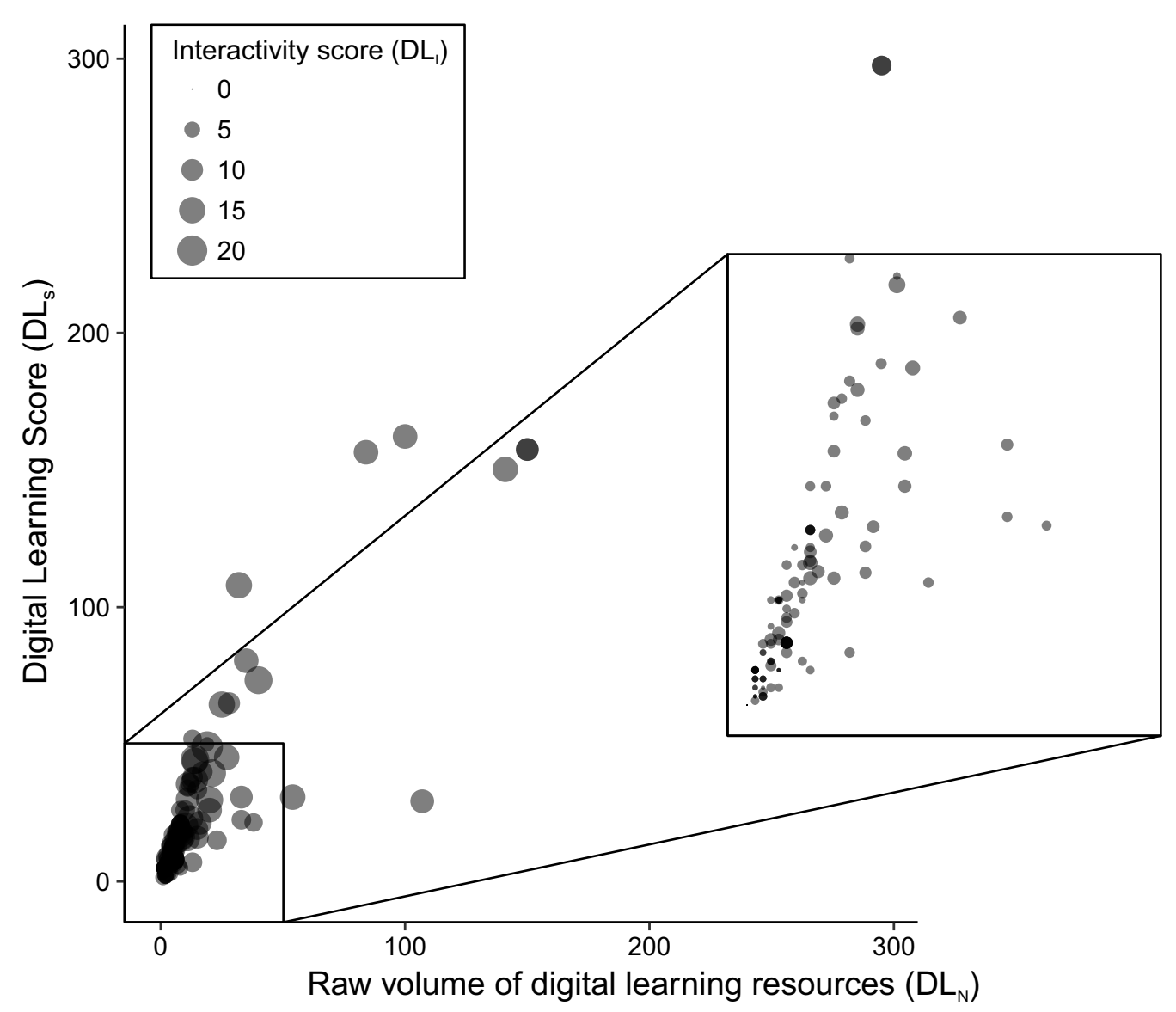

Figure 1. Relationship between raw volume of digital learning resources $\left(\mathrm{DL}_{\mathrm{N}}\right)$ across all digital resource categories (see Table 2) and digital learning score $\left(\mathrm{DL}_{S}\right)$ for all modules in the case study audit. Individual data points are specific modules within the faculty. Data-point size represents an increasing interactivity score $\left(\mathrm{DL}_{\mathrm{I}}\right)$ of all the combined digital learning resources for a given module. The expanded section shows scores in the range $0-50$ for both axes.

\section{Case Study Results}

To address the first main question of this case-study, "To what extent has digital learning been implemented across modules (see Fig. 1), degree programs, program levels, and schools within the faculty?" this section presents results of the digital learning audit across schools, degree programs, and program levels, and highlights some trends in resource use across the faculty.

Learning by school. To determine if there was parity between schools in terms of digital learning resource provisioning, variation in volume of digital learning resources $\left(\mathrm{DL}_{\mathrm{N}}\right)$, their interactivity $\left(\mathrm{DL}_{\mathrm{I}}\right)$, and digital learning scores $\left(\mathrm{DL}_{\mathrm{s}}\right)$ of all modules were compared across schools and with amalgamated values from across the entire faculty. Figure 2 shows significant variation in the volumes (ANOVA: $F=6.35, p<0.001$ ), interactivity (ANOVA: $F=4.11, p=0.008$ ), and scores (ANOVA: $F=4.18, p=0.007$ ) based on digital learning resources between schools, with Schools B and D showing the highest average DLs, particularly with several extreme values within School D. The variation in all boxplots displayed in Figure 2 suggests disparity within as well as between schools. Note that in the case of School D, the main driver of variability appears to be a particular subset of six modules with high numbers of resources but not necessarily high 
interactivity values; a potential issue worth further investigation. Note however, that School D also appears to have the highest average interactivity values within the faculty. School $\mathrm{C}$ appears to have the lowest values across the board, with lowest $\mathrm{DL}_{\mathrm{N}}, \mathrm{DL}_{\mathrm{I}}$, and $\mathrm{DL}_{\mathrm{S}}$ values on average, all below the faculty-level average (Fig. 2).

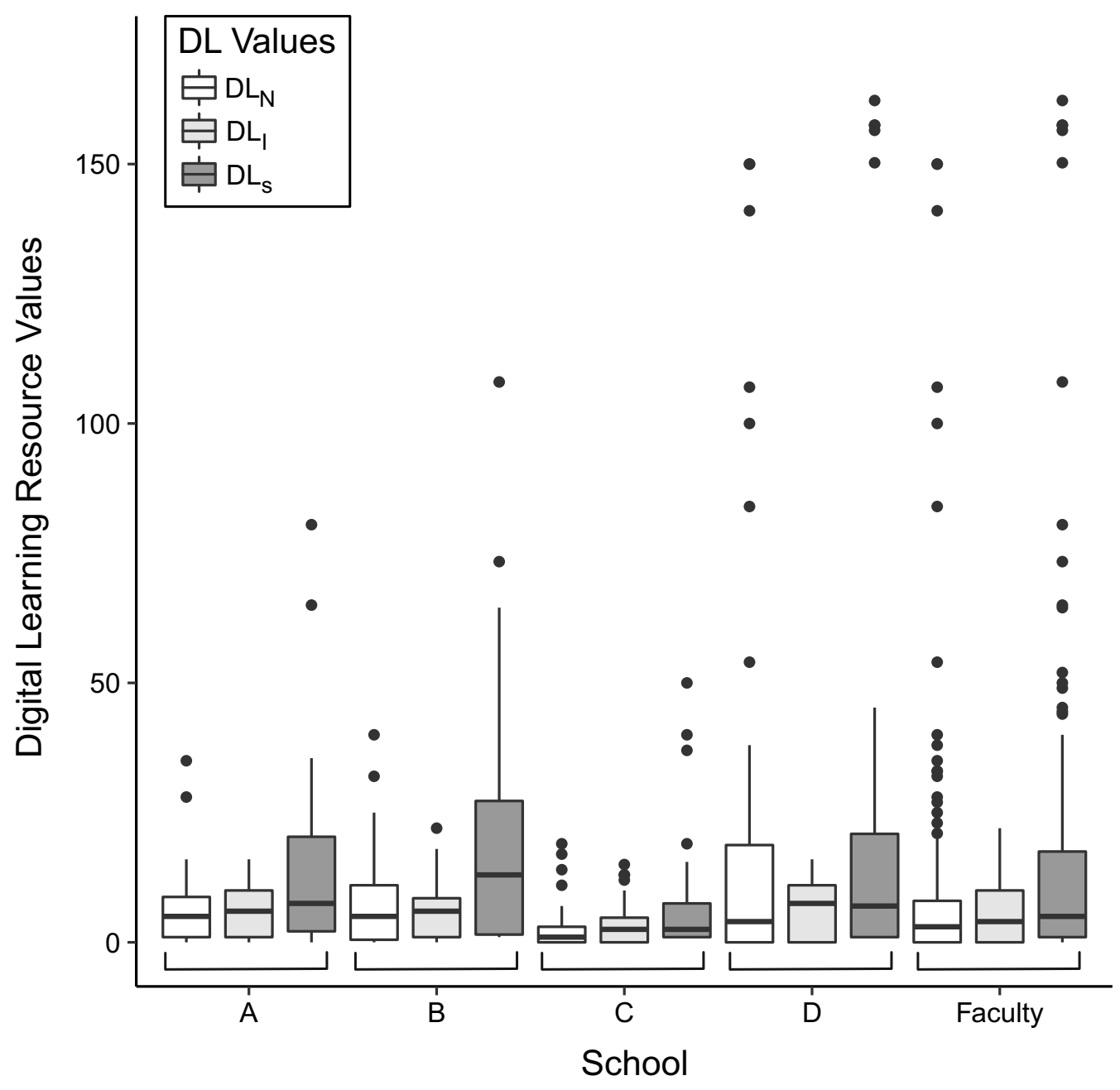

Figure 2. Boxplot of digital learning resource provisioning of schools within the case study faculty (named A-D) and at the faculty level. Each data set is plotted to show the median (line), quartiles (box), and 95\% confidence limits (whiskers) along with outliers (points). The first column of each plot set (white boxes) represents the raw volume of digital learning resources $\left(\mathrm{DL}_{\mathrm{N}}\right)$, light grey boxes represent the cumulative interactivity score $\left(\mathrm{DL}_{\mathrm{I}}\right)$ of all different digital learning resource formats used in each school, and the last of each group - the dark grey boxes - represent the digital learning scores $\left(\mathrm{DL}_{S}\right)$ of each school as calculated using Eqn. 1. Note that for visual clarity, two outliers each at $\sim 300 \mathrm{DL}_{\mathrm{N}}$ and $\mathrm{DL}_{\mathrm{S}}$ for School D and, consequently, the entire faculty data are not shown at this scale.

Digital learning by degree program. By subdividing the school data, a refined examination of individual degree programs can determine the extent to which student experience of digital learning differs by degree program. By presenting the variation in DLs values from all 
modules (compulsory and optional) available to students of a given degree program, a general trend for which degree programs are currently providing greatest exposure to digital learning and the variance between programs can be identified (Fig. 3).

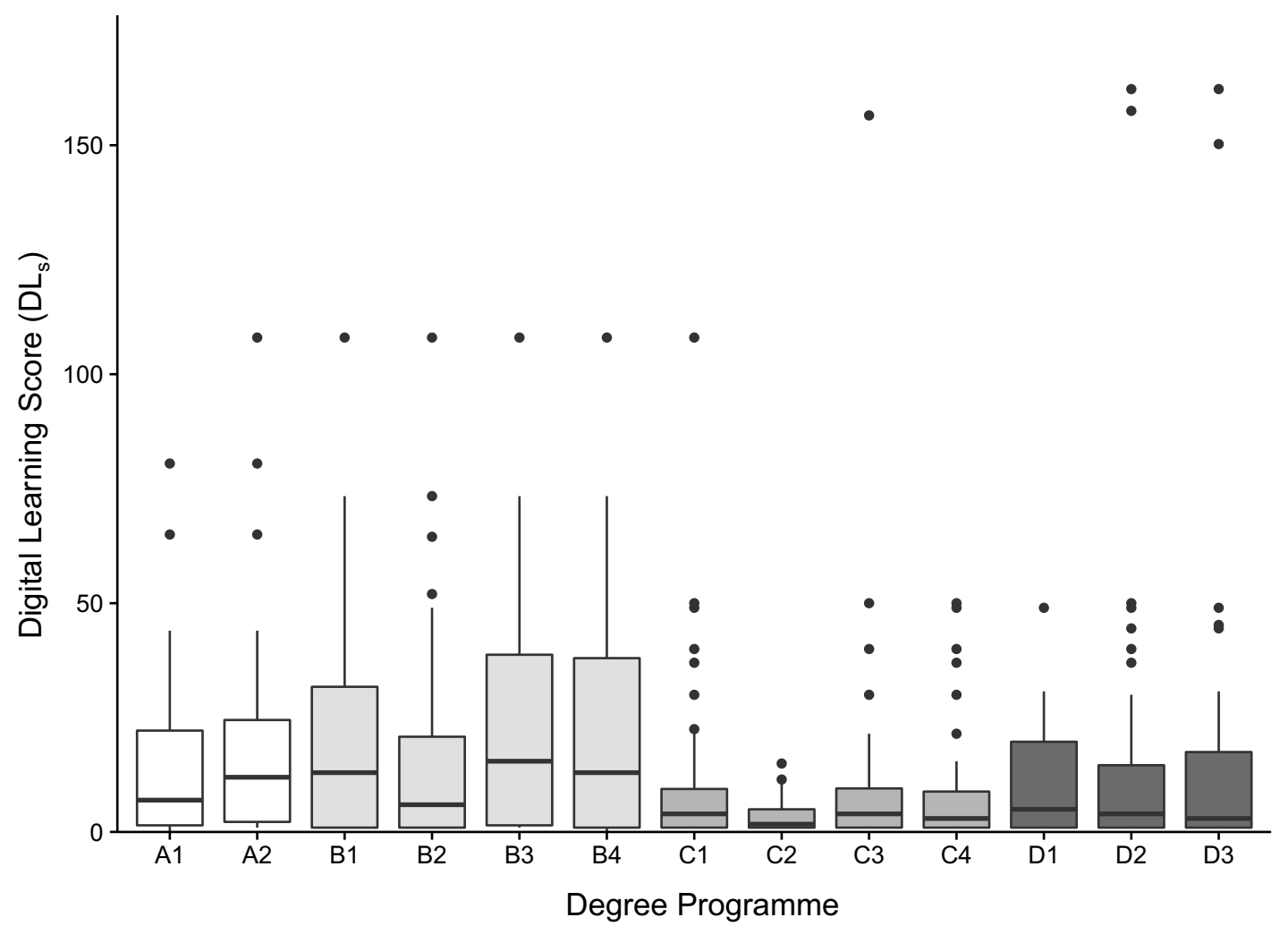

Figure 3. Boxplot of digital learning scores $\left(\mathrm{DL}_{\mathrm{S}}\right)$ for each degree program within the case study faculty. Colors and codes correspond to parent schools (A-D) from Figure 2 such that Programs A1 and A2 (white) fall within School A, Programs B1-B4 (light grey) fall within School B, Programs C1-C4 (medium grey) fall within School C, and Programs D1-D3 (dark grey) fall within School D. Each data set is plotted to show the median (line), quartiles (box), and 95\% confidence limits (whiskers) along with outliers (points). For visual clarity, two outliers each at $\sim 300$ DLs for Programs D2 and D3 are not shown.

As opposed to the school comparisons (Fig. 2), we did not find significant variation among degree programs in their average DLs values (ANOVA: $F=0.58, p=0.86$; Fig. 3 ). It should be borne in mind that these values are based on all the compulsory and optional modules available to students on a given degree program and, as such, the actual experience of students in these programs likely varies based on individual choice of optional modules. The variability around each mean in Figure 3 thus reflects the extent to which module choice can impact student experience of digital learning provision. For example, module choice of students on Program C2 will not affect their exposure to digital learning resources as much as students on Program B3 (or most other degree programs).

Digital learning by program level. It could be expected that as program level increases, general deployment of digital learning resources to support teaching decreases (Gow \& Kember, 1990; Kemp \& Jones, 2007), predominantly due to the increased focus on independent learning 
and further focused study outside of more generic resources/material provided in the latter years of most degree programs. Faculty-level data on $\mathrm{DL}_{\mathrm{S}}$ values across program levels support this, with significant variation among program levels in their DLs values (ANOVA: $F=41.1, p<0.001$ ) and DLs values decreasing on average across Levels 1 to 3 (see Fig. 4).

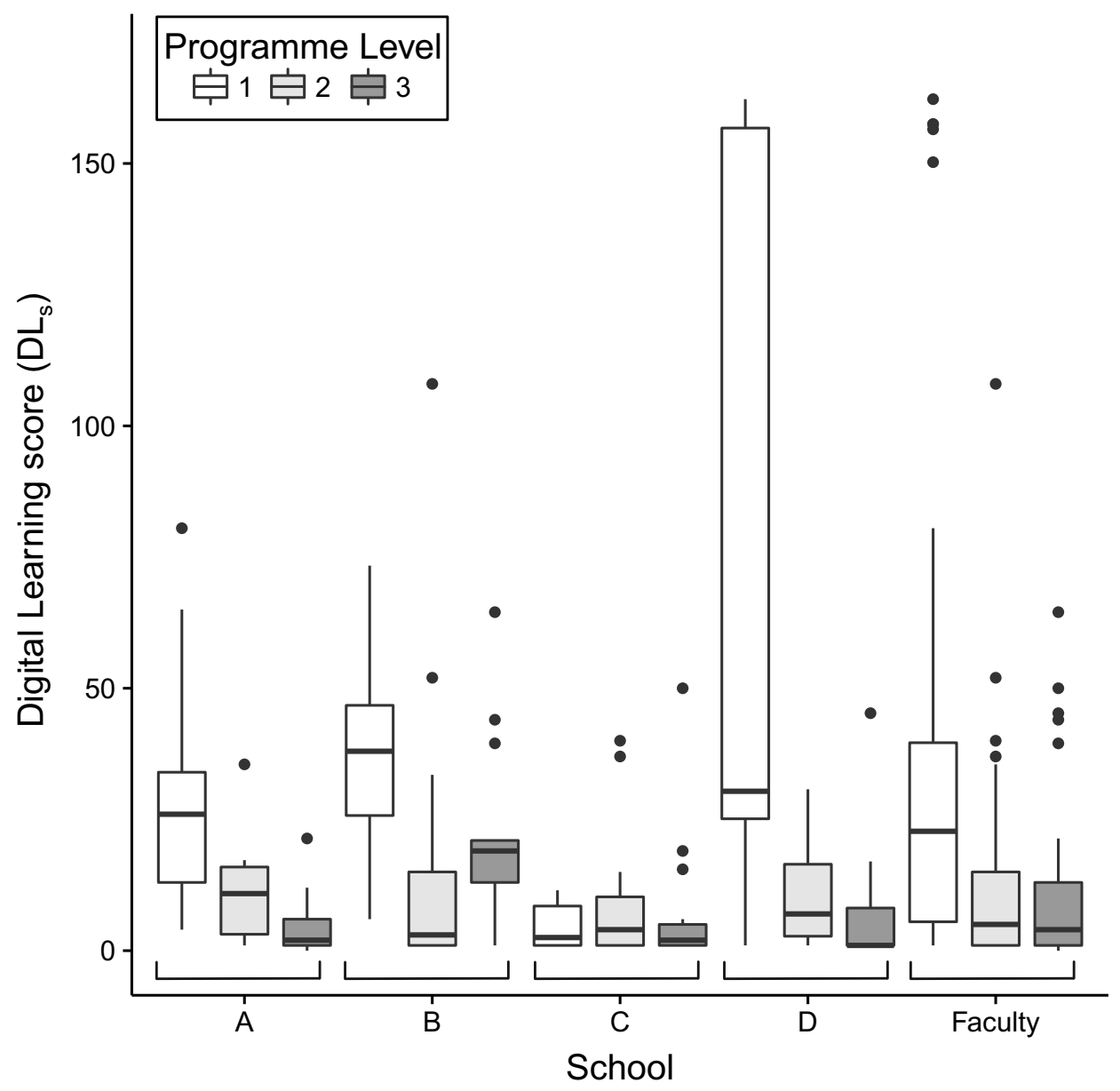

Figure 4. Boxplot of digital learning scores $\left(\mathrm{DL}_{\mathrm{S}}\right)$ of each school $(\mathrm{A}-\mathrm{D})$ and at the faculty level, broken down by degree program level. Each data set is plotted to show the median (line), quartiles (box), and 95\% confidence limits (whiskers) along with outliers (points). Box colors represent program levels such that white boxes represent Level 1 (first year), light grey boxes represent Level 2 (second year), and dark grey boxes represent Level 3 (final year). (For visual clarity, two outliers at $\sim 300 \mathrm{DL}_{\mathrm{S}}$ for School D at Level 1 and the entire faculty are not shown).

Two schools follow this faculty-wide trend of decreasing DLs with increasing program level, with the exception of Schools B and C, which have lowest and highest digital learning scores during the second year of the three years, respectively, highlighting an unusual outlier of activity and inconsistency for further investigation.

Resource-use trends. Moving away from digital learning scores across the faculty, raw volumes of digital learning resource provision $\left(\mathrm{DL}_{\mathrm{N}}\right)$ can reveal which types of resources are most common and in which areas. Indeed, we found significant variation among resource categories in their provision across the faculty when testing for differences in the observed and expected 
provision of different types of resource and assuming as a null hypothesis that resources should be equally implemented irrespective of their format (chi-square test: $X^{2}=2667, p<0.001$ ). Figure 5 shows that online quizzes/coursework, the most interactive resource types (see Table 1), are the most commonly used across the faculty, followed by noninteractive web links and audio/video resources. Games and discussion boards were among the least used resources across the whole faculty in this case study.

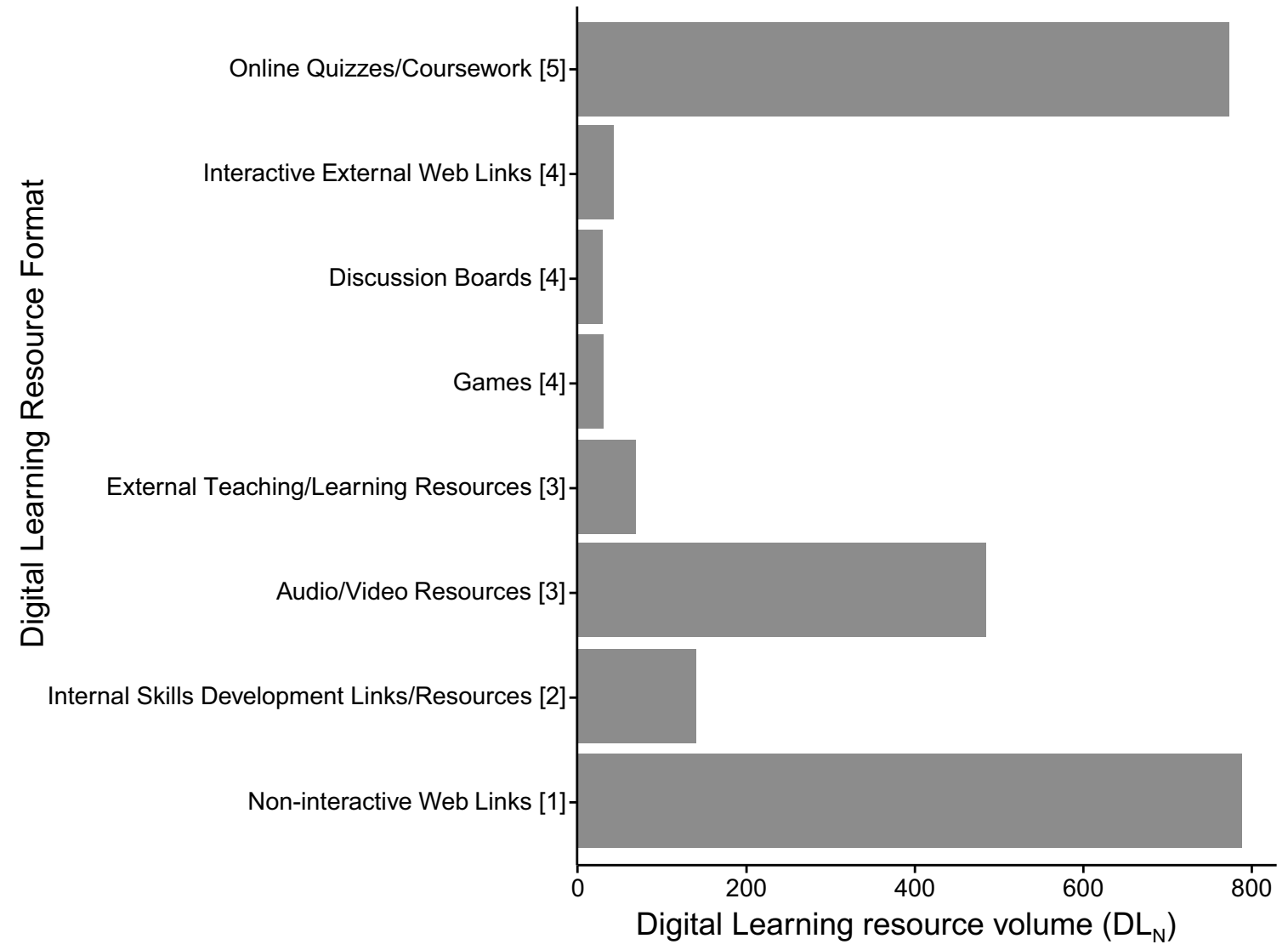

Figure 5. Raw volume of digital learning resources $\left(\mathrm{DL}_{\mathrm{N}}\right)$ by resource category across the entire case study audit. Results are absolute volumes of digital learning resources falling within the categories first outlined in Table 2. Interactivity values used to calculate $\mathrm{DL}_{\mathrm{I}}$ are shown in square brackets, and resource format categories are ordered by interactivity values (Table 2) from most interactive (5) to least interactive (1).

\section{Discussion}

This study addresses the increasing popularity of and advances in digital learning resources and technology (Hiltz \& Turoff, 2005; Kim \& Bonk, 2006), and the subsequent need for higher education institutions to monitor their use of such resources (Mitchell \& Honore, 2007). Students at all levels of education are routinely exposed to a wide range of teaching and learning techniques satisfying the definition of blended learning (Horn et al., 2015). The extent to which digital support of learning is experienced by any individual student will, however, frequently vary depending on the use of such tools across the elements or modules of their program of study. This potentially 
wide variation is typified in the results of the case study above, often due to varying taught content but also the fact that much development in the use of digital resources has been pioneered by individuals who independently develop and experiment with the use of such resources. Indeed "top-down" approaches implementing digital solutions that are not tailored to learning content have a notorious history of poor success (e.g., Lapowsky, 2015; Oppenheimer, 2003). Nonetheless, it is increasingly important to get a meaningful, potentially quantified oversight of the student experience, and data of this type are of increasing value in the rapidly developing area of learning analytics (Sclater \& Mullan, 2017). Yet, to date there is no widely recognized method for auditing digital or blended learning, making such monitoring unprecedented and ultimately challenging (Garrison \& Vaughan, 2008).

An audit of digital support of learning assists in assessing differences in learning experience between students. It is only with this contextual backing that we can understand the perception of teaching and learning by individuals and the entire student body as well as identify trends and developments, such as those observed between levels of study (see Fig. 4). Such insights, as permitted through the accrued data, will prove valuable in directing strategic development as well as highlighting pockets of excellence. Ultimately, such data could also be used to empirically test the general efficacy of blended learning approaches, giving direct evidence to ensure efficient and appropriate development of digital resources. As an example from within the presented case study, for one module it had been identified in a previous year that there was a lack of online support tools. Subsequently, a package of teaching materials was developed to allow revision of the taught material interspersed with a variety of online quizzes. Introduction of this resource was popular with the students and led to a quantifiable significant increase in average attainment on the module (data not shown). This clearly indicates the value of using an audit such as this to identify areas where such support is missing and using it to direct development. It also has great potential for cross-comparing effectiveness of different tools. For example, if resources such as this had been introduced and had no influence or relatively limited impact compared with such changes elsewhere in a program, it could indicate a lack of use or relative ineffectiveness, allowing for rationalized prioritization of development and investigation of resource impact.

\section{Reviewing the Audit Process}

The audit process as outlined proved straightforward to implement, largely due to the highly centralized containment of resources and links to these from the LMS system. Additional resources were identified from staff and, thus, helped ensure the validity of the study. This extra requirement negated the ability to implement possible automated or semi-automated implementation of the audit, although with extensions to the data-gathering process, this remains a possibility, with further developments from many LMS providers increasingly allowing this semi-automated approach (e.g., Blackboard Analytics; see Blackboard, 2017). Table 1 outlines the framework that was used to undertake the audit, along with key considerations for the audit process. This framework outline is valuable for developing audits of such resources at the same scale as that implemented in the case study (a higher education institution faculty) but is also readily adaptable to other scales, such as an institute, individual program or single subject/school. Critically, whether these audits are conducted following this framework or not, it is increasingly important that evaluation of digital learning in higher education take place (McGee \& Reis, 2012; Pahinis, Stokes, Walsh, Tsitrou, \& Cannavina, 2008; Wagner, 2006), especially as students are now, more than ever, being raised in a digitally connected world (Buckingham, 2013; Kennedy, Judd, Churchward, Gray, \& Krause, 2008). 


\section{Analysis of Digital Resources}

For the present case study, scoring was balanced to construct a synthetic statistic equating volume of resource provision $\left(\mathrm{DL}_{\mathrm{N}}\right)$ with resource type and, hence, interactivity $\left(\mathrm{DL}_{\mathrm{I}}\right)$. The premise was that more highly interactive resource types promote greater engagement, which is a key driver for use of digital resources (Davies et al., 2017), but also require more time and resources to develop and deploy. It is not desirable to simply weight by volume of resources since this is likely to encourage and misinterpret the use of large volumes of poor-quality resources. Equally, it is not desirable to have very limited resource availability making for a limited or restrictive digital learning experience. This study aimed to recognize any use of resources that encouraged directed exploration of associated materials and allowed multiple repeated interactions from novel perspectives and modalities, since this best promotes learning (Laurillard, 2002).

The balance reached in the case study was appropriate to the purpose, but in future work and for other audits elsewhere, attempts may be made to score use according to documented efficacy to create a more strongly evidence-based audit of teaching practice. For example, online practice of questions has been shown to subsequently improve performance when answering similar questions in examinations (Bailey, Jensen, Nelson, Wiburg, \& Bell, 2017). A cautionary consideration for this, though, is the fact that learning context may be more important than digital resource type in identifying what best supports the learning experience (Manches, Bligh, \& Luckin, 2012). As such, an additional consideration for future development is tailoring of the scoring for individual programs and modules where there is evidence to support the preferred use of one type of resource over others.

\section{Case Study Outcomes and Analysis}

The results presented above successfully addressed the first key question of this audit: "To what extent has digital learning been implemented across modules, degree programs, program levels, and schools within the faculty?" The second question, "Where are the current gaps in provision and how might these gaps be reduced?" was similarly addressed by analyzing these results. Disparities between schools and program levels were noted, but there were limited differences among degree programs. For example, School $\mathrm{C}$ had the lowest average digital learning scores across the faculty, so it seems likely that targeting additional support at School $\mathrm{C}$ would make a significant contribution to improving parity between schools. Conversely, using modules and areas with high digital learning scores as beacons of good practice may provide examples of how certain areas can improve the implementation of digital learning resources to even out any gaps in provision. A key piece of future work building on this study will be to validate the scoring of resources by testing the efficacy of the component resources, refining the methodology but also permitting appropriate prioritization of development. For example, if the introduction of elements which are currently underutilized in particular areas (e.g., games) correlates with improvements in learning attainment, this would clearly justify development and further deployment of these types of resources. Conversely, if the increased deployment of simple online quizzes produces no further gains in attainment, then this may indicate diminishing returns on investment even for such a relatively simple-to-deploy asset type. Of course, further data on use alongside deployment may be required to properly analyze this type of development, but such data offers a rationalized and justified approach to future digital learning resource development.

Analyzing digital learning by program level generally reveals an overall decrease in the use of digital learning resources across program levels (see Fig. 4), with the highest at Level 1. 
However, Schools B and C display different relationships between program level and digital learning score than the other schools, with $\mathrm{DL}_{\mathrm{S}}$ being lowest in Level 2 and highest in Level 1. Further investigation into the cause of this trend suggests that the higher digital learning scores observed in School $\mathrm{C}$ at Level 2 are likely driven by the high digital focus of several compulsory modules specific to that school at Level 2, and similarly with School B at Level 3, where there could otherwise be expected to be a decrease in digital learning resources with program level (Kemp \& Jones, 2007). These modules provide a different focus than Level 1 modules generally do with respect to digital learning; the nature of digital resources in School C's Level 2 modules are more revision focused and self-directed than the digital content accompanying many Level 1 modules (e.g., audio/video resources, online coursework). This supports the general trend toward greater self-direction throughout a learner's development as described by Grow's (1991) staged self-directed learning model (see Fig. 1 in Grow, 1991), and a concomitant decrease in supporting digital resources and/or a shift in the nature of those resources toward less structured instructional resources seems logical as students are required to rely more on self-directed learning throughout their degrees (Gow \& Kember, 1990; McGee \& Reis, 2012; Pratt, 1988).

\section{Value of Data for Strategic Planning and Monitoring}

As the aim of the case study audit was to determine baseline use of digital learning and identify where support should be subsequently targeted, a few brief examples will now be presented to illustrate how audit results can be used for targeting support from, in this case, the faculty's blended learning team.

Online quizzes/coursework were found to be the most frequently used digital resource type across the Faculty (Fig. 5). This is likely due to the ease with which they can be implemented and their potential for reuse year upon year. This is potentially a good feature to identify since the use of such quizzes has been shown to improve subsequent performance in examination conditions (Bailey et al., 2017), highlighting the value of digital learning resources aimed at providing immediate formative feedback under near-examination settings. As part of the updated digital learning strategy in response to the case study audit, the faculty's blended learning team will be recommending that all modules with written exams implement online quizzes/coursework in some format and highlight the large range of options for the design and use of this type of digital learning resource. This is a logical reaction to identifying a lack of equity across schools and levels, representing a potentially easy gain from a simple-to-implement resource. It is anticipated that greater gains can be made through repeated use of this approach and these analyses in conjunction with student performance and feedback data. For example, deployment of novel tools and the relative benefits of currently potentially underutilized elements (e.g., games, blogs, etc.) can be monitored across programs, schools, and levels to track any changes in student attainment or satisfaction where introduction occurs. This is the real power of using such a tool; it allows the justified development of such resources across the range of courses on offer, supported by an audit trial and subsequent analysis.

The faculty has planned additional audits of digital learning technology in future years at key points to ensure the development of long-term goals is progressing as intended. In the short term, this involves continual support and guidance from the blended learning team to ensure modules can provide digital content where possible, as well as annual reviews of digital learning with key staff and stakeholders from each school (Stages $i x$ and $x$ in Table 1). Over the longer term, faculty-wide implementation of the updated digital learning strategy will result in greater focus on improving digital learning resource provisioning in those areas identified by the case 
study audit to currently have greater need of such resources. This will require several additional audits, albeit perhaps on smaller scales (e.g., a school-level audit rotating annually throughout the four schools). This should satisfy the final aim of the case study audit: "How can similar audits be used in future to ensure the long-term development of digital resources and digital learning strategies?"

\section{Limitations of This Approach}

While the aim of this case study was to increase the parity of digital learning provisioning across the faculty, it should be noted that this may not be the goal of an evaluation audit. Each case will be different, and digital learning should be used only when appropriate and pedagogically relevant (Sclater \& Mullan, 2017). For example, field courses are by their very nature extremely interactive and provide great opportunities for self-directed student learning. Combined with often frequent movement and potentially remote locations, field courses provide an example of a setting in which digital learning is not necessarily appropriate. Additionally, all audits conducted following this framework are limited insofar as they rely on resources being visible in digital space or being identified by the academic staff who teach any given module. The baseline results of our case study are therefore reliable in the sense that repeating the audit based only on the data available on the virtual learning space would produce consistent results, but these results may be modified when consulting with teaching staff. Nevertheless, our audit technique is a good representation of the provisioning of digital learning resources across the faculty in this case, indeed gaining a holistic view of digital learning resource provision and any disparities among schools, programs, program levels, and the types of resources being provided to students.

\section{Potential Extensions to the Framework}

We believe this framework can be applied to different contexts and for various purposes. For example, it could be used within different disciplines or across an institution. It could be used to identify strengths and gaps in provision (as was the aim for our work). It could be used to audit other types of learning resources, such as the extent of examination by coursework or extent of blended learning.

This final section notes several ideas for extending the generalizable audit framework and case study audit presented here (Table 2 and main text, respectively). Several simple additions can expand the scope of the presented audit framework. For example, by including taught postgraduate degrees in the audit rather than undergraduate degrees alone; auditing both digital resources and resources and techniques that are not digital per se but collectively contribute to the definition of blended learning (Garrison \& Kanuka, 2004); or by increasing the scale of the audit to a crossfaculty audit of digital learning, allowing questions to be asked, such as whether parent faculties have equal amounts of disparity between their modules.

Note that all resources were counted here irrespective of student engagement. Determining student engagement with different resources is an alternative and complementary audit that may help to elucidate the value of certain resource types (e.g., Boulos, Maramba, \& Wheeler, 2006; McGarr, 2009). This is potentially a challenging task though, particularly due to the very large volume of data that would need to be collated and analyzed. Currently, the LMS used in our flagship audit (Blackboard, 2017) can collect statistics on the accesses to each item, but the data accumulated is considerable and set to auto-delete after a certain time to avoid the unnecessary accumulation of a vast archive of data. Developments in terms of learning-analytics-type 
approaches are beginning to permit a more accessible and feasible approach to interrogating and utilizing this usage data.

This audit included all taught undergraduate modules within the faculty. This means that modules with widely different formats were included in the same framework. An extension of the digital learning formula presented here (Equation 1) toward a more "blended" framework, could therefore be to include the format of certain modules, as some are inherently more interactive than others (e.g., a practial-based class might a priori be assumed to be more interactive than a module of a traditionally didactic nature, when disregarding teaching methods), contributing to the interactive student experience and the definition of blended learning (Garrison \& Kanuka, 2004). This would require some classification of how interactive each format is, but it could prove useful for those auditors wishing to gain a fuller understanding of the student experience in terms of interactive learning. It is beyond the scope of this study to suggest which formats are most interactive, but for this to be of value, decisions should be made based on existing knowledge of the interactivity of module formats (e.g., Kolb \& Kolb, 2005).

Along these lines, similar extensions could focus exclusively on specific formats that are harder to audit by looking at digital space. For example, in the case study audit, field courses and practical classes commonly had low $\mathrm{DL}_{S}$ values, despite these being some of the most interactive modules available. It may therefore be useful to focus on the use of digital technology outside of the module's virtual space, such as by auditing field courses or practical classes for interactive digital material in the field/laboratory. An illustrative example would be the use of programs such as LabArchives (LabArchives, 2017), which might not appear on the LMS space (Blackboard, 2017) and so may otherwise be missed in a virtual space audit as described here.

A final extension of this framework could be to audit lecture content for within-lecture use of digital or blended learning resources, technology, or techniques (reviewed in O'Flaherty \& Phillips, 2015). This has potential and has been trialled by the case study faculty with some success (data not shown), but the audit techniques need refinement before being presented explicitly.

\section{Conclusions}

This study presents a generalizable framework for audits of digital learning with the aim of encouraging the monitoring of digital learning resources across degree programs, faculties, and even higher education institutions. The case study audit of digital learning is provided as an example of how the presented framework can be implemented to ask and answer questions regarding the use of digital learning at a faculty level. This case study audit was used to set a baseline, from which future audits and follow-up work will expand. There are numerous options for extending the audit framework presented here, as discussed, and we highlight the value of and need for such audits in higher education, particularly in light of the digitally connected environment in which students are being raised. 


\section{Author Contact \\ S.Ross.Res@outlook.com (SRP-JR), V.Volz@leeds.ac.uk (VV), M.K.Lancaster@leeds.ac.uk (MKL), A.Divan@leeds.ac.uk (AD)}

\section{Acknowledgements}

We thank Claire Smith, Rhiannon Prosser, Neil Morris, Juniata Bellham, Phil Lang, Shareen Kininmonth, and other members of the student education service for their help with the logistics of the audit; Kenneth McDowall for guidance and input into the project; and all academic staff who responded to queries regarding specific modules or resources. We also thank two anonymous reviewers for helpful comments on an earlier version of the manuscript that greatly improved its quality. This work did not receive any specific grant from funding agencies in the public, commercial, or not-for-profit sectors. 


\section{References}

Adams Becker, S., Cummins, M., Davis, A., Freeman, A., Hall Giesinger, C., \& Ananthanarayanan, V. (2017). NMC horizon report: 2017 higher education edition. Austin, Texas: The New Media Consortium.

Alpert, D., \& Bitzer, D. L. (1970). Advances in computer-based education. Science, 167, 15821590 .

Bailey, E. G., Jensen, J., Nelson, J., Wiberg, H. K., \& Bell, J. D. (2017). Weekly formative exams and creative grading enhance student learning in an introductory biology course. CBE-Life Sciences Education, 16, 2.

Bigum, C., \& Rowan, L. (2008). Landscaping on shifting ground: Teacher education in a digitally transforming world. Asia-Pacific Journal of Teacher Education, 36, 245-255.

Birch, H. J. (2017). Potential of SoundCloud for mobile learning in music education: A pilot study. International Journal of Mobile Learning and Organisation, 11, 30-40.

Blackboard. (2017). Blackboard Learn. Retrieved from http://anz.blackboard.com/learningmanagement-system/blackboard-learn.aspx.

Boulos, M. N. K., Maramba, I., \& Wheeler, S. (2006). Wikis, blogs and podcasts: A new generation of Web-based tools for virtual collaborative clinical practice and education. BMC Medical Education, 6, 41.

Brown, B., Jacobsen, M., \& Lambert, D. (2014). Learning technologies in higher education. In P. Preciado Babb (Ed.), Proceedings of the IDEAS: Rising to Challenge Conference. Calgary, Canada: Werklund School of Education, University of Calgary.

Buckingham, D. (2013). Beyond technology: Children's learning in the age of digital culture (1st ed.). London: John Wiley \& Sons.

Business, Innovation and Skills Committee, House of Commons. (2016). Teaching excellence framework: Assessing quality in higher education 2016 (1st ed.). London: House of Commons Business, Innovation and Skills Committee.

Christensen, G., Steinmetz, A., Alcorn, B., Bennett, A., Woods, D., \& Emanuel, E. J. (2013). The MOOC phenomenon: Who takes massive open online courses and why? Retrieved from http://dx.doi.org/10.2139/ssrn.2350964.

Collins, J. L., Cook-Cottone, C. P., Robinson, J. S., \& Sullivan, R. R. (2004). Technology and new directions in professional development: Applications of digital video, peer review, and self-reflection. Journal of Educational Technology Systems, 33, 131-146.

Davies, S., Mullan, J., \& Feldman, P. (2017). Rebooting learning for the digital age: What next for technology-enhanced higher education? Retrieved from http://www.hepi.ac.uk/wpcontent/uploads/2017/02/Hepi_Rebooting-learning-for-the-digital-age-Report-93$20 \quad 01 \quad 17$ Web.pdf

Fink, L. D. (2003). Creating significant learning experiences (1st ed.). San Francisco, California: Jossey-Bass. 
Garrison, D. R., \& Kanuka, H. (2004). Blended learning: Uncovering its transformative potential in higher education. The Internet and Higher Education, 7, 95-105.

Garrison, D. R., \& Vaughan, N. D. (2008). Blended learning in higher education: Framework, principles, and guidelines (1st ed.). London: John Wiley \& Sons.

Gilbert, J., Morton, S., \& Rowley, J. (2007). e-Learning: The student experience. British Journal of Educational Technology, 38, 560-573.

Golden, S., McCrone, T., Walker, M., \& Rudd, P. (2006). Impact of e-learning in further education: Survey of scale and breadth. National Foundation for Educational Research: Research Report, 745, 1-91.

Gow, L., \& Kember, D. (1990). Does higher education promote independent learning? Higher Education, 19, 307-322.

Grow, G. O. (1991). Teaching learners to be self-directed. Adult Education Quarterly, 41, 125149.

Hill, J. R., \& Hannafin, M. J. (2001). Teaching and learning in digital environments: The resurgence of resource-based learning. Educational Technology Research and Development, 49, 37-52.

Hiltz, S. R., \& Turoff, M. (2005). Education goes digital: The evolution of online learning and the revolution in higher education. Communications of the ACM, 48, 59-64.

Horn, M. B., Staker, H., \& Christensen, C. M. (2015). Blended (1st ed.). San Francisco, CA: Jossey-Bass.

Jeno, L. M., Grytnes, J. A., \& Vandvik, V. (2017). The effect of a mobile-application tool on biology students' motivation and achievement in species identification: A SelfDetermination Theory perspective. Computers \& Education, 107, 1-12.

Kemp, B., \& Jones, C. (2007). Academic use of digital resources: Disciplinary differences and the issue of progression revisited. Educational Technology \& Society, 10, 52-60.

Kennedy, G. E., Judd, T. S., Churchward, A., Gray, K., \& Krause, K. L. (2008). First year students' experiences with technology: Are they really digital natives? Australasian Journal of Educational Technology, 24, 108-122.

Kiili, K. (2005). Digital game-based learning: Towards an experiential gaming model. The Internet and Higher Education, 8, 13-24.

Kim, K. J., \& Bonk, C. J. (2006). The future of online teaching and learning in higher education. Educause Quarterly, 29, 22-30.

Kolb, A. Y., \& Kolb, D. A. (2005). Learning styles and learning spaces: Enhancing experiential learning in higher education. Academy of Management Learning \& Education, 4, 193212.

Kop, R. (2011). The challenges to connectivist learning on open online networks: Learning experiences during a massive open online course. The International Review of Research in Open and Distributed Learning, 12, 19-38. 
LabArchives. (2017). Go digital with LabArchives. Retrieved from http://www.labarchives.com/classroom-edition/

Lapowsky, I. (2015). What schools must learn from LA's iPad debacle. Wired. Retrieved from https://www.wired.com/2015/05/los-angeles-edtech/

Laru, J., Järvelä, S., \& Clariana, R. B. (2012). Supporting collaborative inquiry during a biology field trip with mobile peer-to-peer tools for learning: A case study with K-12 learners. Interactive Learning Environments, 20, 103-117.

Laurillard, D. (2002). Rethinking university education: A conversational framework for the effective use of learning technologies (1st ed.). London: RoutledgeFalmer.

Leacock, T. L., \& Nesbit, J. C. (2007). A framework for evaluating the quality of multimedia learning resources. Educational Technology \& Society, 10, 44-59.

Littlejohn, A., \& Pegler, C. (2007). Preparing for blended E-learning (1st ed.). London: Routledge.

Manches, A., Bligh, B., \& Luckin, R. (2012). Decoding learning: The proof, promise and potential of digital education. Retrieved from http://apo.org.au/node/32254

McGarr, O. (2009). A review of podcasting in higher education: Its influence on the traditional lecture. Australasian Journal of Educational Technology, 25, 309-321.

McGee, P., \& Reis, A. (2012). Blended course design: A synthesis of best practices. Journal of Asynchronous Learning Networks, 16, 7-22.

Mitchell, A., \& Honore, S. (2007) Criteria for successful blended learning. Industrial and Commercial Training, 39, 143-149.

O'Flaherty, J., \& Phillips, C. (2015). The use of flipped classrooms in higher education: A scoping review. The Internet and Higher Education, 25, 85-95.

Oppenheimer, T. (2003). The flickering mind: The false promise of technology in the classroom and how learning can be saved (1st ed.). New York: Random House.

Pahinis, K., Stokes, C. W., Walsh, T. F., Tsitrou, E., \& Cannavina, G. (2008). A blended learning course taught to different groups of learners in a dental school: Follow-up evaluation. Journal of Dental Education, 72, 1048-1057.

Papastergiou, M. (2009). Digital game-based learning in high school computer science education: Impact on educational effectiveness and student motivation. Computers \& Education, 52, 1-12.

Pratt, D. D. (1988). Andragogy as a relational construct. Adult Education Quarterly, 38, 160172.

R Core Team. (2016). R: A language and environment for statistical computing. Retrieved from https://www.R-project.org/

Reiser, R. A. (2017). Eight trends affecting the field of instructional design and technology: Opportunities and challenges. In F-Q. Lai \& J. D. Lehman (Eds.), Learning and knowledge analytics in open education. Switzerland: Springer International Publishing. 
Sclater, N., \& Mullan, J. (2017). Learning analytics and student success-Assessing the evidence. Retrieved from http://repository.jisc.ac.uk/6560/1/learninganalytics and student success.pdf

Sheehan, M. C., \& Mihailidis, P. (2007). Deans of change: Keeping their schools current with the digital revolution, raising enough money to make that happen and putting together diverse staffs are among the challenges facing the people who run the nation's journalism and mass communication schools. American Journalism Review, 29, 40-44.

Song, L., \& Hill, J. R. (2007). A conceptual model for understanding self-directed learning in online environments. Journal of Interactive Online Learning, 6, 27-42.

Traxler, J., \& Kukulska-Hulme, A. (2005). Evaluating mobile learning: Reflections on current practice. Retrieved from http://oro.open.ac.uk/12819/1/mlearn05 Traxler\%26KukulskaHulme.pdf

Wagner, E. D. (2006). On designing interaction experiences for the next generation of blended learning. In C. J. Bonk \& C. R. Graham (Eds.), The handbook of blended learning: Global perspectives, local designs. London: John Wiley \& Sons.

Weigel, V. B. (2002). Deep learning for a digital age: Technology's untapped potential to enrich higher education (1st ed.). San Francisco, CA: Jossey-Bass.

Wong, L. (2013). Student engagement with online resources and its impact on learning outcomes. Journal of Information Technology Education, 12, 129-146.

Yin, R. K. (2014). Case study research: Design and methods (5th ed.). London: SAGE Publications Ltd. 